Trivent Publishing

(C) The Authors, 2016

Available online at http://trivent-publishing.eu/

Engineering and Industry Series

Volume Power Systems, Energy Markets and Renewable Energy Sources in

South-Eastern Europe

\title{
The Region of Crete: An Integrated and Sustainable Energy Planning
}

\author{
Virginia Manasaki, Maria Apostolaki, Michael Golovanis \\ Vice Government for Energy and Industry, Region of Crete, Greece, \\ vmanasaki@gmail.com; maria.apostolaki@gmail.com; mgolo@tee.gr
}

\begin{abstract}
The island of Crete is a special case concerning energy due to its geopolitical position, size and energy self-efficiency, the sharp fluctuation in energy demand, but mostly due to the absence of electrical interconnection with the mainland. An integrated Energy Planning is therefore essential for providing a key tool for implementing sustainable regional development. The Region of Crete is the first Region in Greece that has developed an integrated Regional Energy Planning, which examines the current energy needs, considers and evaluates all the possible sources of electricity production and their participation in the energy mix up to 2050. Following the National and European energy policies, guidelines and goals, and taking advantage of the large capacity of renewable energy, the Region of Crete through its Energy Planning aims to maximize renewable energy production and promote energy efficiency for reducing dependence on fossil fuels and greenhouse gas emissions. Through collaboration with research and academic institutions and European partners, the Region of Crete develops and implements innovative actions and programs for achieving the goals set by the European Directive "20-20-20" for Energy and Environment.
\end{abstract}

This is an Open Access article distributed in accordance with the Creative Commons Attribution Non Commercial (CC-BY-NC-ND 4.0) license, which permits others to copy or share the article, provided original work is properly cited and that this is not done for commercial purposes. Users may not remix, transform, or build upon the material and may not distribute the modified material (http://creativecommons.org/licenses/by-nc/4.0/) 


\section{Keywords}

Crete; sustainable; regional; energy planning; efficiency; renewable

\section{Introduction}

The island of Crete is located in the south-eastern part of Europe (Figure 1). It covers an area of $8,303 \mathrm{~km}^{2}$ and is the largest island in Greece and the fifth largest one in the Mediterranean Sea. The population of the island is approximately 680.000 (Hellenic Statistical Authority 2011), most of it located in the three major cities located on the north coast of the island. During the summer, the island of Crete attracts over 4.000.000 visitors, which causes a sharp fluctuation in energy demand and significantly increases the energy consumption of the island.

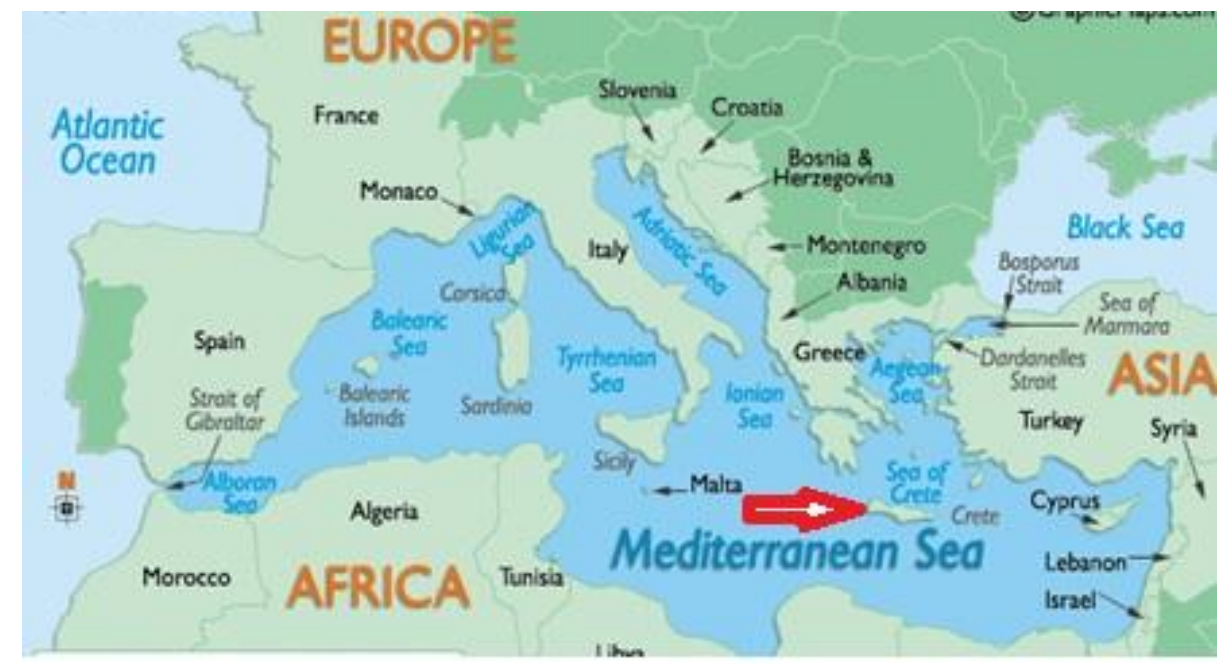

Fig. 1. Location

The island of Crete is a special case concerning energy, as it is an isolated power system, energy self-efficient with large capacity of renewable energy sources [1]. Furthermore, the geopolitical position and size of the island as well as the recent increasing interest concerning the research for the exploitation of hydrocarbons, place it in the spotlight of energy developments in Southeastern Europe and the Mediterranean Sea as a potential hub, involving it in European strategic energy projects (two PCI's projects: Euroasia Interconnector, Eastmed pipeline - Figure 2). 


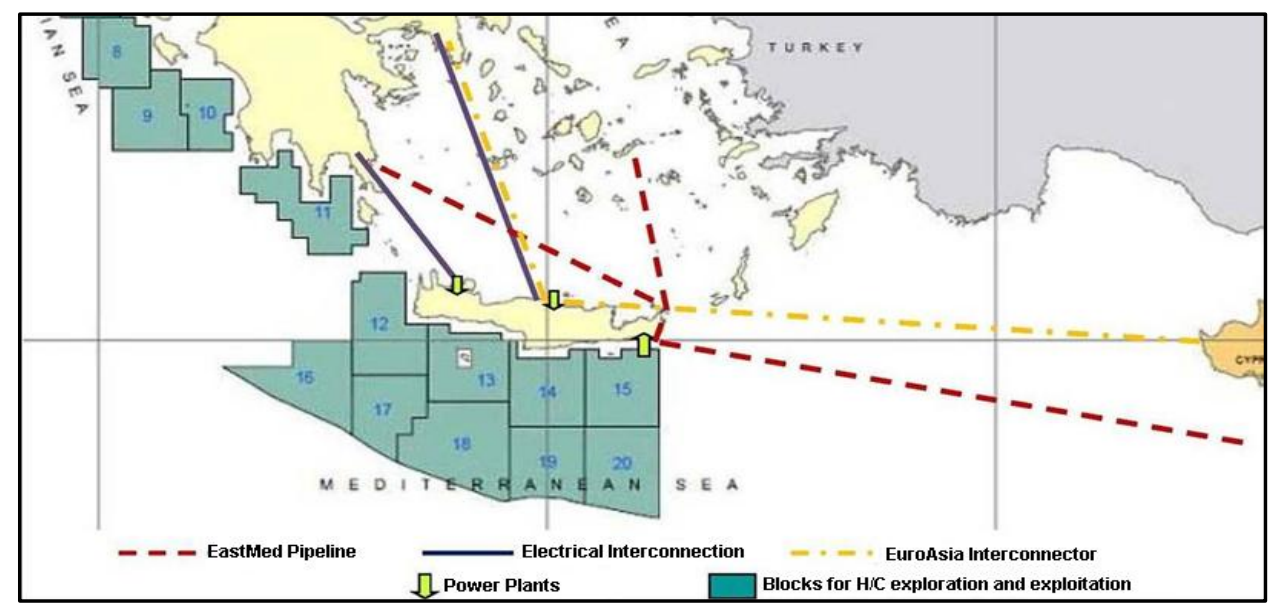

Fig. 2. Energy projects involving Crete

Three thermal plants currently generate the energy production in Crete (Figure 3), while renewable energy covers an annual share of $20-24 \%$, which is close to the upper technical and operational limit for a non-interconnected electric system [2].

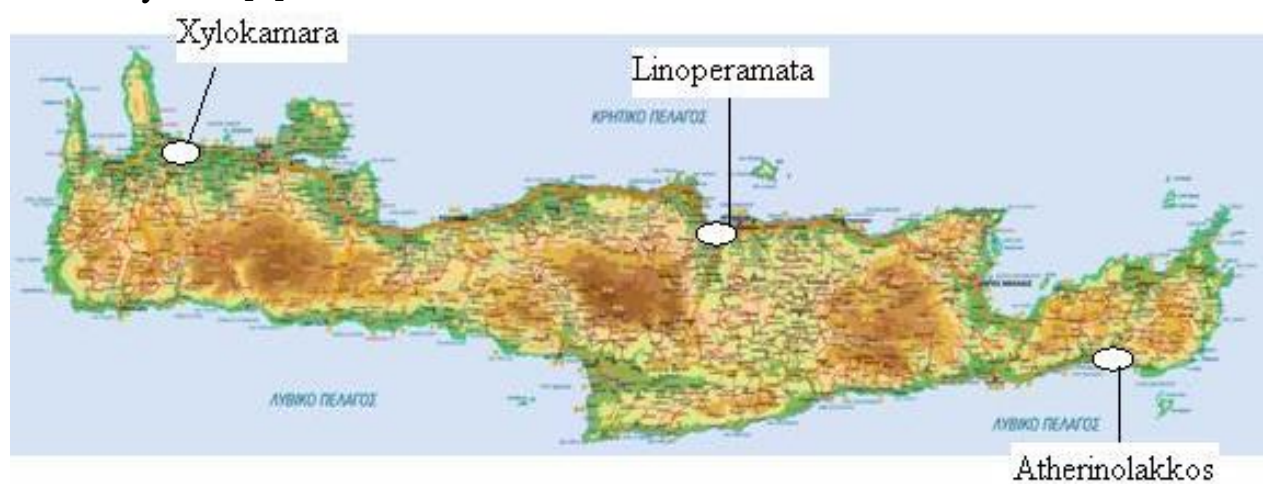

Fig. 3. Power Plants using oil and diesel fuels

According to the data of the Hellenic Electricity Distribution Network Operator [3], for 2014 the electricity system of Crete had total installed capacity 1102,4 MW, in which the RES participation was 283,1 MW (Figure 4). 


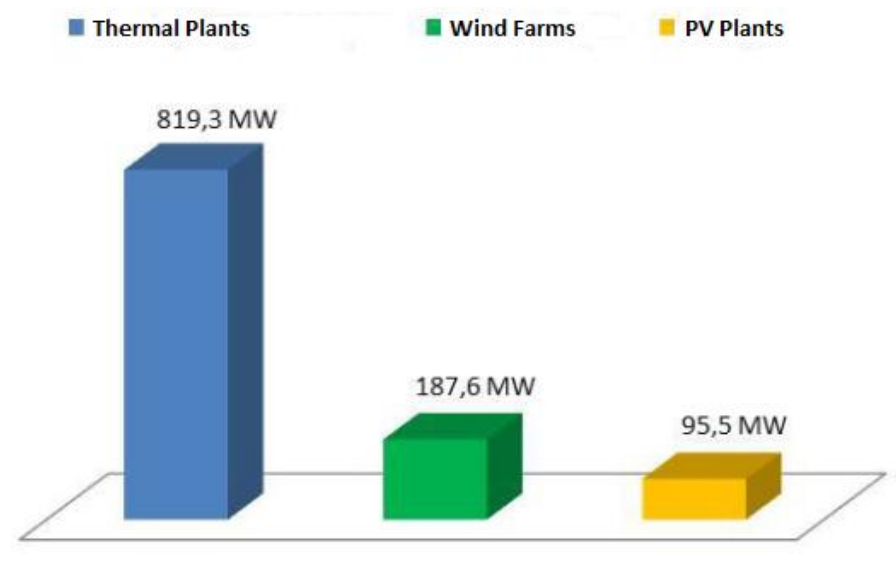

Fig. 4. Installed capacity for 2014

Aiming to deal with the major issue of energy security and sustainable energy development and also to align with the EU environmental directives, National and European regulations that require the gradual reduction of fuel oil use (mainly in power generation), the Region of Crete has developed an Integrated Energy Planning. This is an important scientific tool for policymaking and sustainable regional development that takes into account economic, environmental and social factors, as well as national and European policies.

\section{Regional Energy Planning}

Energy demand keeps increasing as energy affects all sectors of economy, such as agriculture, tourism, industry, public and private services, scientific and technological development. A sustainable energy-producing model is therefore essential for promoting energy efficiency in accordance with National and European energy policies, for using energy resources in a sustainable way, reducing fossil fuels dependence and securing the island's energy stability.

An integrated Energy Planning has developed in the Region of Crete for providing a key tool for implementing sustainable regional development. It is a dynamic model that aims to provide basic guidelines to energy sustainability taking into consideration all possible sources of electricity production and their participation in the energy mix.

\section{A. Principles and structure}

The Regional Energy Planning analyses the current energy demand, considers and evaluates all the possible sources of electricity production and their 
participation in the energy mix up to 2050. It is based on the formulated national and European policies, principles, guidelines and goals, emphasizing on the sustainable development of energy projects on the island. Its principal aim is to secure the island's energy supply and sufficiency, reduce energy dependence and take advantage of the vast RES potential of the island. Through the integrated energy planning of Crete, energy saving and energy efficiency are promoted in favour of progressive and effective reduction of $\mathrm{CO}_{2}$ emissions for achieving the goals set by the European Directive "20-20-20" for Energy and Environment.

All available data are collected, evaluated and analysed for producing the current energy profile of the Region of Crete. Based on 2013 data, the energy balance is produced and future energy demand in all sectors as well as energy production, are estimated up to 2050. Several scenarios are produced and analysed, following the trends and the progress on the electrical interconnection with the mainland, the participation of natural gas in the energy mix, etc and comparative assessment is made based on various criteria.

\section{B. Scenarios}

The integrated Regional Energy Planning of Crete analyses the energy needs and evaluates the current and the future energy balance of the island. Taking into consideration the electrical interconnection with the mainland and all the possible sources of electricity production and their participation in the energy mix, the energy planning develops gradually up 2050.

The integrated Sustainable Energy Planning produces scenarios that mainly differ in:

- Basic infrastructure for the electricity sector (interconnection of limited or large capacity)

- RES Development

- Development of a natural gas system

- Energy saving

In particular, the following scenarios have been produced:

- Maintenance of the current situation without interconnection (BAUBusiness As Usual)

- Maintenance of the thermal power generation units, energy saving actions and decentralized RES development

- Electric interconnection of limited capacity, maintenance of conventional electricity production (after modernization of installations), increased RES development 
- Increased RES development, electric interconnection of large capacity

- No electric interconnection, increased RES development, maximization of energy saving, gradual independence from fossil fuels by 2040-2050

- Increased importation of Natural Gas in all sectors (industry, households, transportation), including a terminal LNG and distribution network, no electric interconnection

- Natural Gas importation, electric interconnection of limited capacity, increased RES penetration

- Natural Gas importation, no electric interconnection, maximization of energy saving.

\section{Conclusions}

For the Region of Crete energy stability, sustainable development and social prosperity is of major importance. Thus, an integrated Regional Energy Planning has developed for providing a key tool for implementing sustainable regional development. The Planning analyses the current energy needs, considers and evaluates all the possible sources of electricity production and their participation in the energy mix up to 2050 .

Renewable energy and energy saving are the only pillars of long-term perspective in the context of reducing dependence on fossil fuels and significantly reducing greenhouse gas emissions. The island of Crete has a vast solar and wind potential and the development of renewable energy contributes to the development of the island. However, the future development of RES projects in Crete should be implemented gradually and reasonably, in accordance with the spatial planning framework and having positive impact on regional and local development opportunities, with priority given to small or medium scale projects.

Furthermore, the development of renewable energy depends on the electrical interconnection with the mainland, which has not yet implemented, although being the subject for discussion and study for many years. The Energy Planning proves that interconnection of limited or large capacity is significant for securing energy supply and system stability, as well as reducing the energy costs. By implementing the electrical interconnection, new perspectives will be created for renewable energy production, which will result in the independence on fossil fuels and the reduction of the greenhouse gas emissions, combined with the increase of energy efficiency. 
Moreover, the natural gas importation in Crete's energy mix offers a direct supply solution with less emissions and at a low cost, since the small-scale LNG technologies are expected to be mature and inexpensive.

\section{References}

[1] Theocharis Tsoutsos, Maria Drandaki, Niki Frantzeskaki, Eleftherios Iosifidis, Ioannis Kiosses "Sustainable energy planning by using multicriteria analysis application in the island of Crete" Energy Policy 37 (2009): 1587-1600

[2] Emmanuel S. Karapidakis, Yiannis A. Katsigiannis, Pavlos S. Georgilakis and Emmanuel Thalassinakis "Generation expansion planning of Crete power system for high penetration of renewable energy sources." Materials Science Forum 670 (2011): 407-414

[3] http://www.deddie.gr/en 